\title{
Response to "Comment's on the Story of the Silent Killer, a History of Hypertension: Its Discovery, Diagnosis, Treatment, and Debate"
}

\author{
Jonathan Kalehoff ${ }^{1} \cdot$ Suzanne Oparil ${ }^{2}$ \\ Accepted: 3 December 2020 / Published online: 3 February 2021 \\ (C) The Author(s), under exclusive licence to Springer Science+Business Media, LLC part of Springer Nature 2021
}

Dear Reader,

Thank you so much for your interest and feedback on this review of the history of hypertension. We truly appreciate you highlighting the impactful work of the Iranian physicians, Razi and Ibn Sina, and their path breaking observations, which were likely related to hypertension. Moreover, despite hours of research, we had not found information on either figure until you provided us with this fascinating information. Thank you! While we hoped to have as comprehensive a review as possible, the broad scope of the work, which ranged from ancient history to present day, made it very difficult to include all contributors to our knowledge of hypertension in this paper. We acknowledge there are vast numbers of details which had to be omitted from the work - due both to length restrictions and our own humble limitations to research all of the nuances and important figures in this grand history. We are grateful to others such as yourself who are willing to engage in sharing more information, ideas, and opinions on this subject. We are excited to continue learning along with others about this fascinating history and cannot thank you enough for your comments!

Best wishes to you in all your endeavors!

Publisher's Note Springer Nature remains neutral with regard to jurisdictional claims in published maps and institutional affiliations.

Jonathan Kalehoff

jpkalehoff@uabmc.edu

Suzanne Oparil

soparil@uabmc.edu

1 Pulmonary \& Critical Care Medicine, The University of Alabama at Birmingham, THT 422, 1720 2nd Avenue South, Birmingham, AL 35249-0006, USA

2 Division of Cardiovascular Disease, Department of Medicine, University of Alabama at Birmingham, THT 422, 1720 2nd Avenue South, Birmingham, AL 35249-0006, USA 